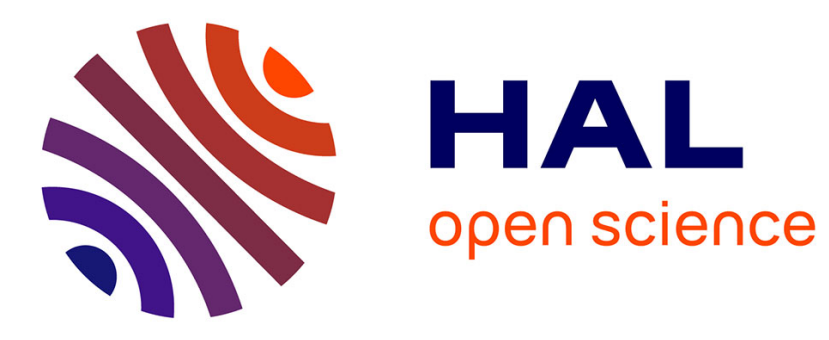

\title{
Comparison of conventional and High Velocity Compaction of alumina powders
}

David Souriou, Patrice Goeuriot, Olivier Bonnefoy, Gérard Thomas, Sylvain Drapier, Stéphane Bourdin, Ludovic Lazzarotto

\section{To cite this version:}

David Souriou, Patrice Goeuriot, Olivier Bonnefoy, Gérard Thomas, Sylvain Drapier, et al.. Comparison of conventional and High Velocity Compaction of alumina powders. 11th International Ceramics Congress and 4th Forum on New Materials, Acireale, Sicily, Italy, June 4-9, 2006, Jun 2006, Acireale, Italy. pp.893-898, 10.4028/www.scientific.net/AST.45.893 . hal-00128232

\section{HAL Id: hal-00128232 \\ https://hal.science/hal-00128232}

Submitted on 31 Jan 2007

HAL is a multi-disciplinary open access archive for the deposit and dissemination of scientific research documents, whether they are published or not. The documents may come from teaching and research institutions in France or abroad, or from public or private research centers.
L'archive ouverte pluridisciplinaire HAL, est destinée au dépôt et à la diffusion de documents scientifiques de niveau recherche, publiés ou non, émanant des établissements d'enseignement et de recherche français ou étrangers, des laboratoires publics ou privés. 


\title{
Comparison of conventional and High Velocity Compaction of alumina powders.
}

\author{
D. Souriou ${ }^{1, a}$, P.Goeuriot ${ }^{1, b}$, O. Bonnefoy ${ }^{1, c}$, G. Thomas $^{1, d}$, S. Drapier $^{1, e}$, S. \\ Bourdin $^{2, f}$, L. Lazzarotto ${ }^{2, g}$ \\ 1: Ecole Nationale Supérieure des Mines de Saint Etienne, UMR CNRS 5146 and 5148, 158 Cours \\ Fauriel, 42023 Saint-Etienne Cedex 2 France. \\ 2. CETIM, 7 Rue de la Presse, BP802, 42952 Saint Etienne Cedex 09 France. \\ asouriou@emse.fr ; bpgoeurio@emse.fr ; cobonnefoy@emse.fr ; ${ }^{\mathrm{a}}$ gthomas@emse.fr ; \\ edrapier@emse.fr ; stephane.bourdin@cetim.fr ; ${ }^{\mathrm{e}}$ ludovic.lazzarotto@cetim.fr
}

Keywords: Alumina, compaction, density, sintering.

\begin{abstract}
Ceramic compacts can be usually prepared by uniaxial pressing in a die made of stainless steel, but the pressure applied is limited and density gradients occur in many cases. Recently a new forming method in powder metallurgy, the High Velocity Compaction (HVC) has been applied to ceramic powders. This method is similar to conventional pressing but consists in making an ram falling down at a very high speed to the upper punch. The kinetic energy is converted into a strike that produces a high pressure in a really short time. By controlling the kinetic energy, it is possible to apply a desired pressure that can be extremely high (up to $1 \mathrm{GPa}$ ) without any damage for the tool. The aim of the study is to compare the process conditions and the properties of green compacts elaborated by the two methods (conventional and HVC) for a similar forming pressure: forming pressure, green density (homogeneity), pore size distribution of the tablets, and then the sintering behavior, the shrinkage, the final density and microstructure of the ceramic material are studied.
\end{abstract}

\section{Introduction}

Some studies performed during the sixties and seventies have shown that the increase of powder compaction velocity could allow to reach higher densities [1,2,3,4,5,6]. These studies were based on explosion compaction techniques (or gas canons). Works in this domain have stopped for obvious industrialization difficulties concerning explosive uses, for insufficient machine lifespan, for reliability, and for difficulties to control the energy delivered.

Nowadays, a new press generation developed by Hydropulsor allows to control the kinetic energy. CETIM is equipped with such a machine able to to reach punch velocities up to $11 \mathrm{~m} \cdot \mathrm{s}^{-1}$ and to develop an energy up to $20 \mathrm{~kJ}$. This equipment has also a new "multi-shot" feature with a strike frequency of 3 to 5shots per second. This method called High Velocity Compaction (HVC) [7], can be described as follows: a 350kg ram is propelled at a very high speed from a height up to 160 millimeters on the upper punch. The compaction force then results from the dissipation of the kinetic energy of a mass in movement acting at a very high speed.

Fig. 2 indicates that the forming pressure increases almost instantaneously. The first peak is the main compression stress peak and is considered as the forming pressure, the second peak is due to rebounds of the ram. The powder bed contained in the forming die is then compressed in only $3 \mathrm{~ms}$. This technology would allow to decrease production time and tools cost and to tend to a cleaner process (less or no binder to be degraded after all) while proposing materials with better properties. 
However, compaction mechanisms occurring during HVC process and their effects on parts characteristics need to be more clearly identified in order to make progress in industrial part feasibility.

The aim of this study is to compare the properties of ceramic compacts formed by HVC with conventional pressing (axial pressing). Green and post sintering properties of compacts elaborated by the two methods will be compared using various techniques of characterization.
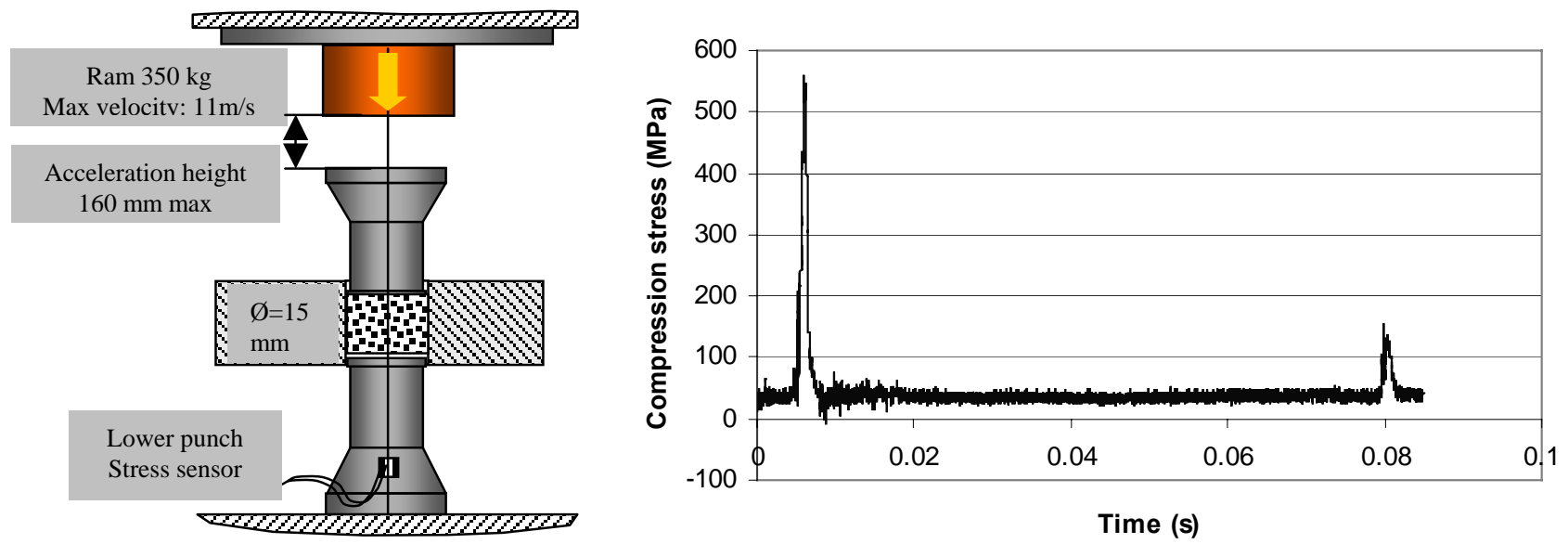

Fig. 1: Schematic of HVC device.

Fig. 2: Compression stress peaks versus time during a HVC experiment.

\section{Devices used for compact elaboration and analyses.}

In this study, alumina has been studied as it is a basic material in ceramic science, it is hard, brittle, and have no plasticity nor viscous deformation at room temperature. The alumina powder analysed is a SM8 alumina (mean grain size $\mathrm{d} 50=0.4 \mu \mathrm{m}$ ) containing $2.5 \%$ in weight of PVA binder. This powder is spray dried and provided by the firm BAIKOWSKI CHIMIE (France). The mean spraydried particle size is about $10 \mu \mathrm{m}$. The alumina specific mass is $3.987 \mathrm{g.cm}-3$.

All compacts are formed in a carbide $15 \mathrm{~mm}$ diameter cylindrical die. Conventional compacts are formed by using a hydraulic press (QUIRI). Compaction stress is determined with a gauged manometer, the pressure is estimated within a tolerance of plus or minus $10 \mathrm{MPa}$ at maximum pressure of $800 \mathrm{MPa}$. The compaction displacement is $200 \mathrm{~mm} \cdot \mathrm{min}^{-1}$, the desired stress is maintained 3 seconds, and then stress is released with a relaxation displacement of $200 \mathrm{~mm} . \mathrm{min}^{-1}$. The green densities are determined from mass (with PVA included) and geometrical measurements of the compacts.

For sake of analysis needs, the compacts are previously debinded at $600^{\circ} \mathrm{C}$ for $1 \mathrm{~h}$ with heating rate and cooling rate of $1^{\circ} \mathrm{C} \cdot \mathrm{min}^{-1}$. After debinding of compacts, the pore size distribution is determined by a mercury porosimeter and by conventional BET analysis (respectively autopore IV and ASAP2000 from MICROMETRICS).

Dilatometric analysis (SETSYS 16/18 dilatometer from SETARAM) allows studying the sintering behavior of compacts. The dilatometric analysis cycle of this study is as follows: temperature increase up to $1550^{\circ} \mathrm{C}$ (heating rate of $5^{\circ} \mathrm{C} \cdot \mathrm{min}^{-1}$ ) and immediate decrease of temperature (cooling rate of $20^{\circ} \mathrm{C} \cdot \mathrm{min}^{-1}$ ) down to room temperature. Densities of sintered samples are determined by Archimedes' weighting. 
After sintering, samples are observed with S.E.M. techniques. Photographs are then analysed with ANALYSIS software ${ }^{\circledR}$ in order to determine the particle size distribution (PSD) and the equivalent diameter (average grain diameter).

\section{Main results.}

Fig. 3 shows a classic curve of green density versus the forming pressure for HVC compacts. Three complementary points obtained by conventional pressing are added. "HVC" refers to compacts formed by HVC and “conv” refers to compacts conventionally formed.

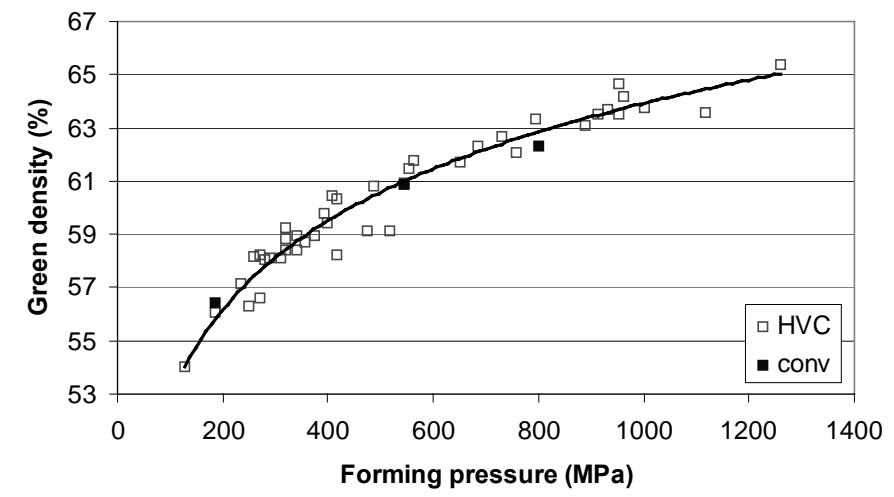

Fig. 3: Green density of HVC and conventional compacts as function of stress.

It seems that the forming process has no influence for the compaction of this alumina powder, the key parameter being the applied pressure. To compare the two methods, samples obtained at the same pressure (187, 546 and $796 \mathrm{MPa}$ ) and the compact obtained only by HVC at $1260 \mathrm{MPa}$ (this stress cannot be performed by conventional method without risks of tools break) are characterized.

Debinded sample densities are indicated in the Table 1. Above $550 \mathrm{MPa}$, the HVC compact density is greater than the one of conventional compacts.

\begin{tabular}{|c|c|c|c|c|c|}
\hline \multicolumn{3}{|c|}{ HVC compacts. } & \multicolumn{3}{c|}{ Conventional compacts. } \\
\hline Main stress peak [MPa] & Density [\%] & Reference & Forming pressure [MPa] & Density [\%] & Reference \\
\hline 187 & 52.4 & 187HVC & 187 & 52.9 & 187CONV \\
\hline 546 & 56.5 & 546HVC & 546 & 56.2 & 546CONV \\
\hline 796 & 58.7 & 796HVC & 796 & 57.5 & 796CONV \\
\hline 1260 & 59.4 & 1260HVC & - & - & - \\
\hline
\end{tabular}

Table 1: characteristics of conventional and HVC debinded compacts.

\section{Mercury porosimetry.}

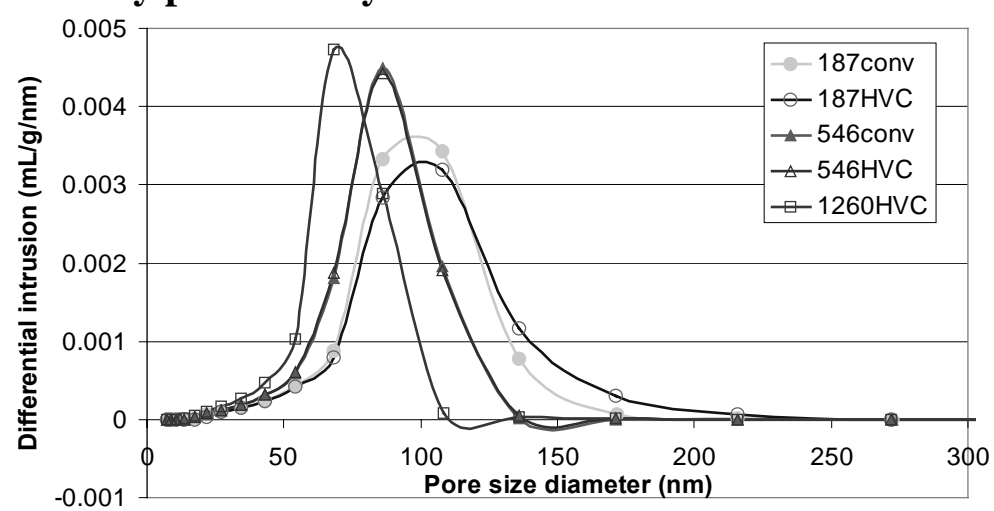

Fig. 4: Dependence of the pore size distribution on the forming pressure and forming method. 
The pore size diameter distribution given in Fig. 4 shows that an increase in forming pressure shrinks the pore size and refines the peak width. For the same forming pressure, pore size distribution is identical for a conventional and a HVC compact.

\section{BET analysis.}

In addition of mercury porosimetry, BET analysis have been performed to have information on contacts between grains. Specific surface areas of compacts are given in Table 2, within a $10 \%$ error:

\begin{tabular}{|c|c|c|c|c|c|}
\hline Sample & 187conv & 187HVC & 546conv & 546HVC & 1260HVC \\
\hline Measured specific surface area $\left(\mathrm{m}^{2} \cdot \mathrm{g}^{-1}\right)$ & 9.1 & 8.8 & 9.1 & 8.6 & 8.8 \\
\hline
\end{tabular}

Table 2: Specific surfaces of conventional and HVC compacts.

Specific surfaces for the two forming process stand between 8.6 and $9.1 \mathrm{~m}^{2} \cdot \mathrm{g}^{-1}$, these variations are not significant. Indeed Fig. 5 shows that compacts exhibit mesoporosity (pore diameter between 2 and $50 \mathrm{~nm}$ ): nitrogen adsorption at high relative pressure is linked with mesopores. The volume of nitrogen adsorbed increases with the forming pressure, and especially for HVC compacts.

Fig. 6 represents the derivating of the specific adsorbed nitrogen volume with respect to the pore diameter. This representation is equivalent to mercury differential intrusion for mesopore size distribution. HVC compacts exhibit more pores with a diameter greater than $10 \mathrm{~nm}$ relatively to conventional compacts that have more pores with a pore diameter inferior to $10 \mathrm{~nm}$. This suggests that density distribution appears more homogeneous in HVC compacts.

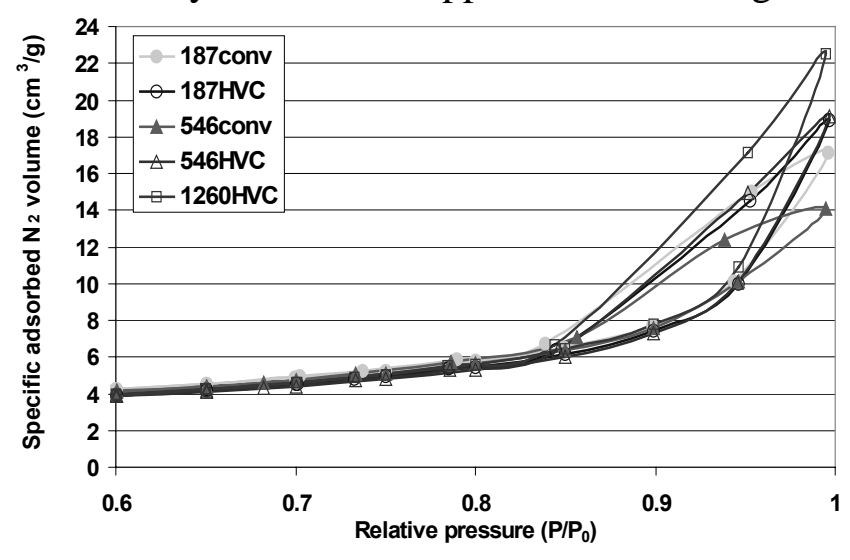

Fig. 5: Adsorption hysteresis of conventional and HVC compacts elaborated at various pressures.

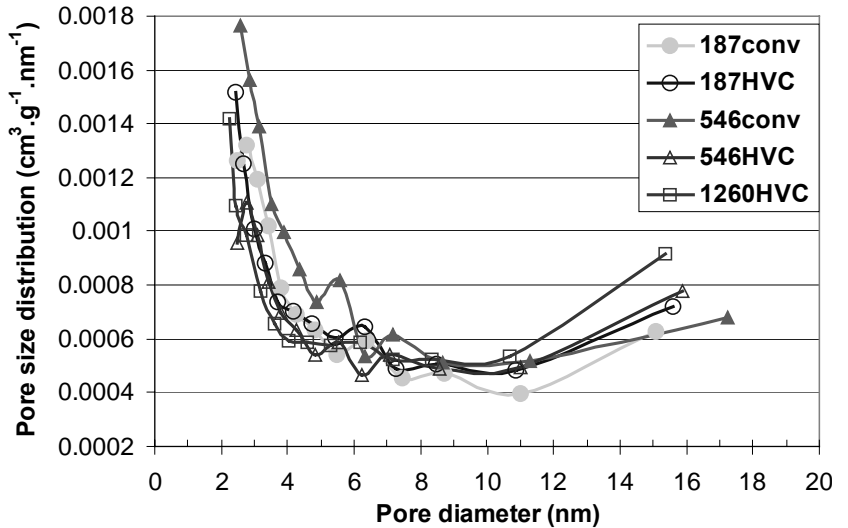

Fig. 6: Pore size distribution of conventional and HVC compacts elaborated at various pressures.

\section{Comparative dilatometric analysis.}

To determinate the sintering behavior of compacts elaborated at different pressures and for the both forming methods, and to evaluate the anisotropy coefficient of compacts, axial and radial dilatometric measurements are performed. Anisotropy coefficient is defined as the ratio between axial and radial relative shrinkage. Final densities and anisotropy coefficients are represented in Fig. 7 and Fig. 8. 


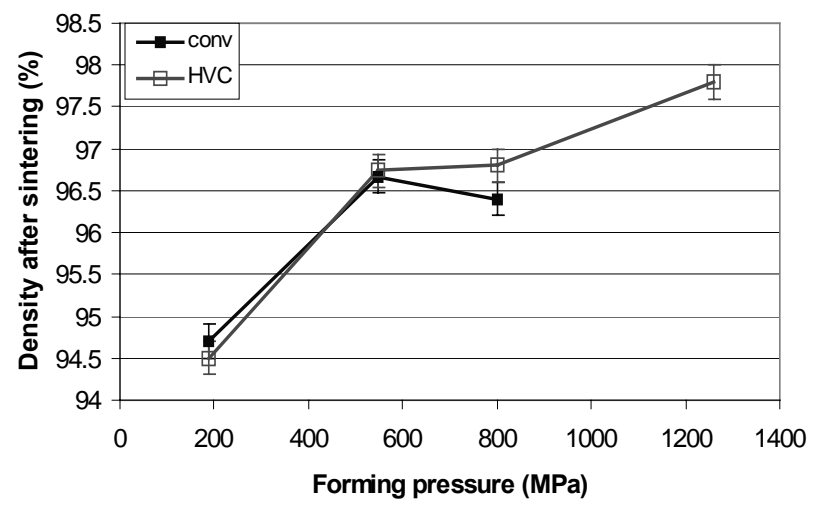

Fig. 7: Density after sintering of conventional and HVC compacts as a function of forming pressure.

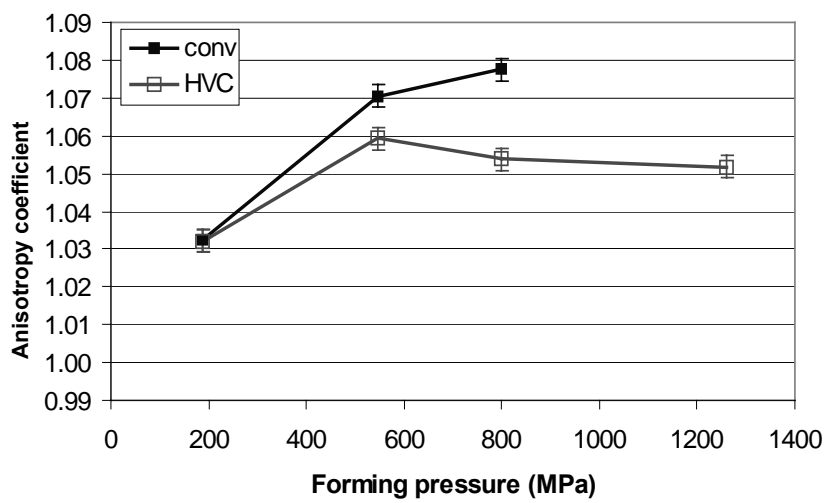

Fig. 8: Anisotropic coefficient of conventional and HVC compacts as a function of forming pressure.

As expected, densities after sintering increase with the forming pressure. The anisotropy coefficient for HVC compacts is very close to 1 whereas conventional compacts seem to be more anisotropic. This shows that the initial state of a HVC compact is more homogenous than a conventional one at the same forming pressure. It confirms the BET analysis observations.

The sintering behavior of compacts formed at 187, 546 and $1260 \mathrm{MPa}$ is shown in Figs. 9 and 10. At an equivalent forming pressure comparison of superposed dilatometric curves in Fig. 9 shows that the sintering behavior doesn't depend on the method applied to form the compact. The sintering temperature corresponding to the maximum of relative shrinkage velocity, exhibit a tendency to decrease when increasing the forming pressure. The temperature shift between compacts formed at $187 \mathrm{MPa}$ and at $1260 \mathrm{MPa}$ is about $50^{\circ} \mathrm{C}$.

Fig. 10 deduced from dilatometric data allows correlating macro and micro properties [8]. It is confirmed that starting sintering with a higher density improves the final density (for sintering without threshold).

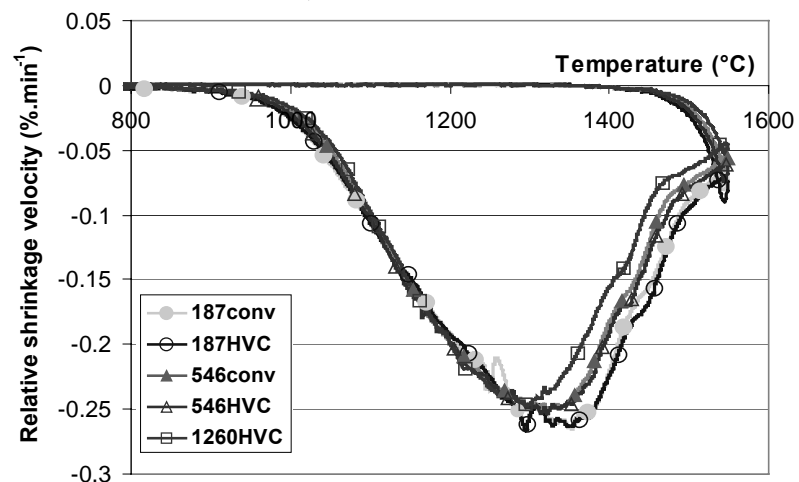

Fig. 9: Shrinkage velocity versus temperature of compacts formed by conventional pressing and HVC at various pressures.

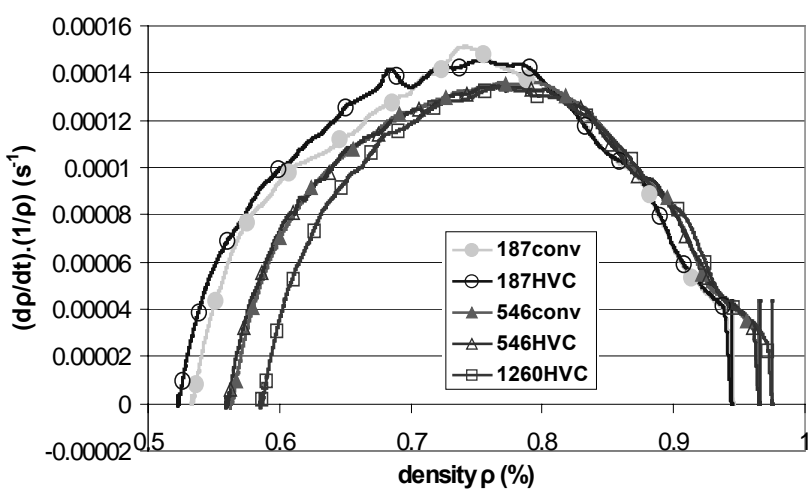

Fig. 10: Dependence of the densification velocity on the relative density curves of compacts formed by conventional pressing and HVC at various pressures.

\section{Microstructure determination.}

Samples micrographs have about 800 grains. The results of particle size distribution and average grain diameter are given in Fig. 11 and Table 3. 


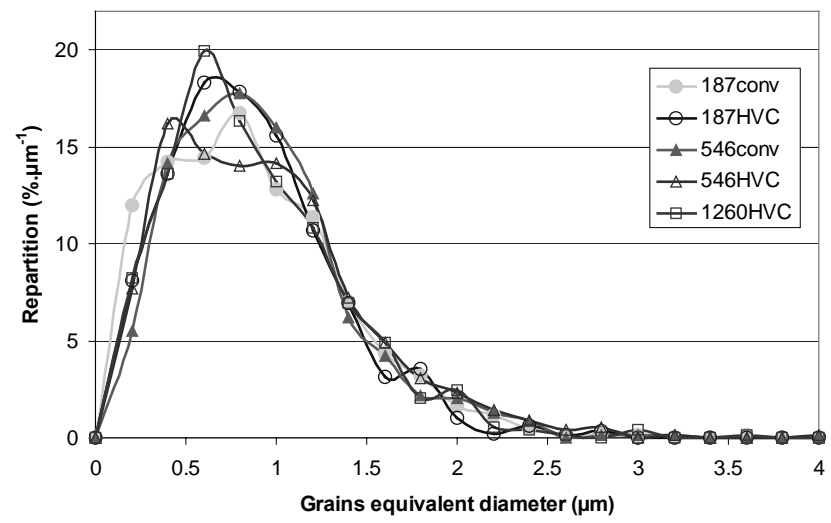

Fig. 11: Equivalent particle diameter distribution for samples sintered at $1550^{\circ} \mathrm{C}$ without threshold.

\begin{tabular}{|c|c|c|}
\hline & $\begin{array}{c}\text { Average grain } \\
\text { diameter }(\mu \mathrm{m})\end{array}$ & $\begin{array}{c}\text { Standard } \\
\text { deviation }\end{array}$ \\
\hline 187conv & 1.10 & 0.42 \\
\hline 187HVC & 1.07 & 0.38 \\
\hline 546conv & 1.13 & 0.39 \\
\hline 546HVC & 1.17 & 0.45 \\
\hline 1260HVC & 1.10 & 0.40 \\
\hline
\end{tabular}

Table 3: Average grain diameter of samples sintered at $1550^{\circ} \mathrm{C}$ without threshold.

For all forming pressures, the average grain size differences between the two forming methods remain in the measurement tolerance and are not significant.

\section{Conclusion of comparison on conventional pressing and HVC and prospective.}

The comparison study with the alumina powder has shown that for identical forming pressures, below 550MPa, initial and final densities of conventional and HVC compacts are the same, but HVC seems to improve density for higher pressures. Even if no differences on macropores size distribution have been observed, it seems that HVC process leads to slightly more homogeneous compacts. The forming pressure is a key parameter for the sintering behavior. As the anisotropy coefficient of HVC compacts is closer to 1 than for conventional compacts, large HVC pieces should be less deformed during sintering. Anyway, there are no significant microstructural differences between two compacts formed at the same pressure by HVC or conventional pressing for a sintering without threshold.

The advantages of HVC method are to be confirmed. Experiments with a $50 \mathrm{~mm}$ diameter carbide die will be carried out in order to study the density homogeneity and to collect compaction data for mathematical modeling.

\section{References:}

[1] W.T. Montgomery and H. Thomas: Powder Metallurgy Vol. 6 (1960), p. 125

[2] E. La Rocca and J. Pearson: Review of Scientific Instruments Vol. 29, No.10 (1958), p. 848

[3] R.J. Brejcha: Engineer's Digest Vol. 23, No.7 (1962), p.77

[4] E.M. Stein, J.R. Van Orsdel and P.V.Schneider: Metal Progress Vol. 85, No.4 (1964), p. 83

[5] G.Geltman: New Methods For The Consolidation of Metal Powders, Plenum Press (1967), p.75

[6] S. Wang and R. Davies: Proc. $9^{\text {th }}$ International Machine Tool Design and Research Conference, Birmingham, Pergamon (1968)

[7] L. Lazzarotto, F. Doré, C.H. Allibert, P. Doremus, P. Goeuriot, O. Lame C. Chervin: Sintering'05, Grenoble 2005 Proceedings

[8] D. Lance, F. Valdivieso and P. Goeuriot: J. Eur. Ceram. Soc. Vol 24(9) (2004), p. 2749. 